\title{
Division of Frosting Type and Frosting Degree of the Air Source Heat Pump for Heating in China
}

\author{
Rui Tang, Feng Wang *, Zhihao Wang and Weibo Yang \\ College of Electrical, Energy and Power Engineering, Yangzhou University, Yangzhou, China
}

\section{OPEN ACCESS}

Edited by:

Mengjie Song,

Beijing Institute of Technology, China

Reviewed by:

Long Zhang,

Beijing Institute of Technology, China

Zhihua Wang,

Xi'an Jiaotong University, China

${ }^{*}$ Correspondence:

Feng Wang

wangfengseu@163.com

Specialty section:

This article was submitted to

Process and Energy Systems

Engineering,

a section of the journal

Frontiers in Energy Research

Received: 12 May 2021

Accepted: 28 July 2021

Published: 25 August 2021

Citation:

Tang $R$, Wang $F$, Wang $Z$ and Yang $W$ (2021) Division of Frosting Type and Frosting Degree of the Air Source Heat

Pump for Heating in China.

Front. Energy Res. 9:708478.

doi: 10.3389/fenrg.2021.708478
The frosting type and frosting degree of the outdoor heat exchanger of air source heat pump (ASHP) in the heating season are greatly affected by the local environmental temperature and humidity. China has a vast territory, and the climate varies greatly in different regions. Therefore, when the ASHP is running in different climate zones for heating in winter, there are significant differences in the frosting type and frosting degree. In order to achieve deeper understanding of frost formation and provide more accurate guidance for the suitability application of antifrosting and defrosting technologies, a study on the division of frosting type and frosting degree was performed in this work. Based on the three-phase diagram of water and combined with the theory of phase change dynamics, the outdoor heat exchanger of the ASHP in the heating season was divided into four states: neither frosting nor condensation, condensation, condensation frosting, and sublimation frosting, and the proportion of each state in a typical city in different climate zones was calculated. The results showed that more than $80 \%$ of the heating seasons in Nanjing, Shanghai, Wuhan, Changsha, Xi'an, and Harbin had the frosting phenomenon. Sublimation frosting was the main frosting type in Xi'an, Beijing, and Harbin, while Chongqing was all condensation frosting. Moreover, a frosting model was developed and the frosting degree was divided into mild frosting, moderate frosting, and heavy frosting, according to the performance attenuation of the ASHP under frosting conditions. The proportion of each frosting degree in a typical city was achieved. About $50 \%$ of the heating seasons in Nanjing and Changsha were distributed in the heavy frost area and $100 \%$ in Chongqing.

Keywords: air source heat pump, heating, frosting type, frosting degree, frosting model

\section{INTRODUCTION}

The air source heat pump (ASHP) is widely used as cooling and heating source in China for building air conditioning due to its advantages of having cooling and heating functions, energy saving, environmental protection, flexible installation, etc. Its application plays an important role in improving energy efficiency, promoting energy conservation and emission reduction (Xu et al., 2020; Zhang et al., 2018a; Song et al., 2018; Zhang et al., 2017; Amer and Wang, 2017). However, when an ASHP runs for heating in winter, there is a problem of frost formation on the surface of its outdoor fin-tube heat exchanger. The growth of frost layer leads to the deterioration of the working condition of the ASHP and the attenuation of its heating performance (Dong et al., 2012; Song et al., 2016; Wang et al., 2017; Zhang et al., 2018b). To reduce the adverse influence caused by frosting, it is significant to develop effective antifrosting and defrosting technologies. Undoubtedly, understanding the process and mechanism of frost formation is the prerequisite. 
There were three main aspects in the research of frost formation. Firstly, the visualization was carried out and the microscopic characteristics of the frost growth were achieved. Kim et al. (2016) observed the average height, radius, number, and density of frost crystals at the initial stage of frosting on fin surfaces with different contact angles by experiments. As the contact angle increased, the average height and number of frost crystals increased, while the radius and density decreased. Lee and Lee (2018) conducted frosting experiment on a cold surface and found that, in the early stage of frosting, plumes of frost crystals formed on the cold surface, which grew in a one-dimensional manner. Secondly, the influences of important parameters such as air temperature and humidity on the frost growth were studied. Li et al. (2017) studied the effects of air temperature, relative humidity, and cold surface temperature on the frosting of copper plate. It was found that the frost layer growth rate increased when the air temperature or relative humidity increased. Thirdly, the operating performances of the ASHP under different frosting conditions were obtained. Wu et al. (2017) simulated numerically frosting on the surface of finned tube heat exchanger. It was found that the frost on the surface of the finned tube heat exchanger affected the airflow, and the pressure drop dropped by half within $50 \mathrm{~min}$. Guo et al. (2006) conducted an experimental study of an air conditioner under frosting conditions. The heating capacity and coefficient of performance had increased in the early. With the frosting process progressing, the performance began attenuating and declined faster in the later.

There were two types for frost formation, namely, condensation frosting and sublimation frosting. In addition, the frost growth rate and mass were greatly affected by the environmental temperature and humidity, so the operating performances of the ASHP were also different under different environmental conditions. China has a vast territory and the climate varies greatly in different regions. Therefore, when the ASHP is running in different climate zones for heating in winter, there are significant differences in frosting types and degree on the surface of the outdoor heat exchanger. Based on the frost growth rate (Wang, 1997; Wang et al., 2009), frosting was divided into a heavy frosting area, general frosting area, low-temperature frosting area, mild frosting area, and nonfrosting area. However, the frosting degree under different frosting types was still unclear. In order to achieve deeper understanding of frost formation and provide more accurate guidance for the suitability application of antifrosting and defrosting technologies, a study on the division of the frosting type and degree of the ASHP was performed in this work.

In this paper, based on the three-phase diagram of water and combined with the theory of phase change dynamics, the outdoor heat exchanger of the ASHP in heating seasons was divided into four states: neither frosting nor condensation, condensation, condensation frosting, and sublimation frosting, and the proportion of each state in typical cities in different climate zones was calculated. Moreover, a frosting model was developed and simulated by Matlab, and the frosting degree was divided into mild frosting, moderate frosting, and heavy frosting, according to the performance attenuation of the ASHP
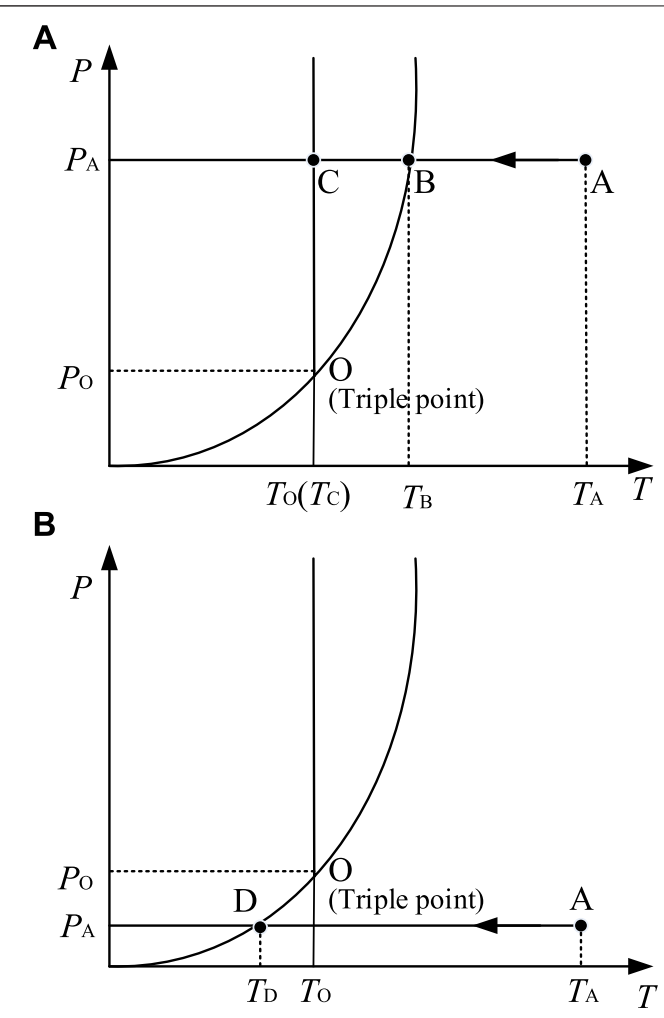

FIGURE 1 | The state change of water vapor in the air shown in the three-phase diagram: (A) the partial pressure of water vapor in the air greater than the triple-point pressure; (B) the partial pressure of water vapor in the air less than the triple-point pressure.

under frosting conditions. The proportion of each frosting degree in typical cities in different climate zones was achieved.

\section{DIVISION OF FROSTING TYPE \\ Division Principle Based on the Three-Phase Diagram}

When the ambient air passes over the fin surface, whether and how the water vapor in the air undergoes a phase change depends on the temperature and humidity of the air and the surface temperature of the fin. The theoretical process can be expressed in the three-phase diagram of water, as shown in Figure 1. In order to simplify the analysis process, it is assumed that the difference between the fin surface temperature and the ambient air temperature $\Delta t$ is constant, which is $10^{\circ} \mathrm{C}$ (Wang et al., 2009; Yu et al., 2011).

When the humidity of the air is high, the partial pressure of water vapor in the air is greater than the triple-point pressure of water. Point A shown in Figure 1A is the water vapor state point corresponding to the ambient air, and its temperature is $T_{\mathrm{A}}$. The partial pressure of water vapor is $P_{\mathrm{A}}$, point $\mathrm{B}$ and $\mathrm{C}$ are equal to the partial pressure of water vapor in the air and intersect the gasliquid line and the solid-liquid line respectively, and their temperatures are $T_{\mathrm{B}}$ and $T_{\mathrm{C}}$, respectively. 


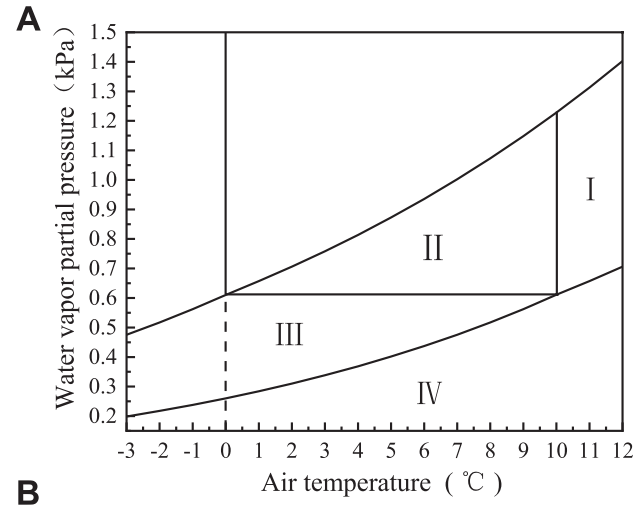

B

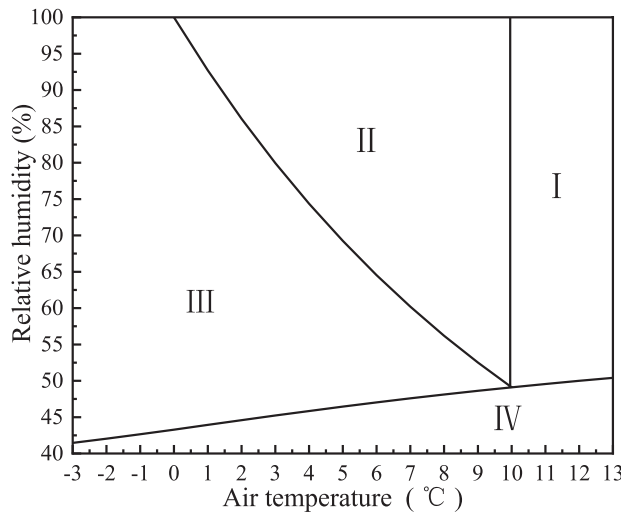

FIGURE 2 | Conversion of the frosting types between the three-phase diagram of water and temperature-humidity diagram: $(\mathbf{A})$ the frosting types divided in the three-phase diagram of water; $\mathbf{( B )}$ the frosting types divided in the temperature-humidity diagram.

When $T_{\mathrm{A}}-T_{\mathrm{B}}>\Delta t$, the final state of the air after passing through the fins falls between $\mathrm{A}$ and $\mathrm{B}$. At this time, the water vapor in the air still exists in a gaseous form. In this case, the water vapor does not undergo a phase change, and the ASHP is in a neither frosting nor condensation condition.

When $T_{\mathrm{A}}-T_{\mathrm{B}} \leq \Delta t<T_{\mathrm{A}}-T_{\mathrm{C}}$, the final state of water vapor in the air falls in the liquid phase zone, and the ASHP is in a condensation condition at this time.

When $T_{\mathrm{A}}-T_{\mathrm{C}} \leq \Delta t$, the water vapor in the air has undergone two phase changes; that is, it first condenses into liquid droplets on the surface of the fin and then frosts. At this time, the ASHP exhibits a condensation frosting condition.

When the humidity of the air is low, the partial pressure of water vapor in the air is less than the triple-point pressure of water. Point A shown in Figure 1B is the water vapor state point corresponding to the ambient air, and its temperature is $t_{\mathrm{A}}$. The partial pressure of water vapor is $P_{\mathrm{A}}$, and point $\mathrm{D}$ is the state point at which the partial pressure of water vapor in the air is equal and intersects with the gas-solid line, and its temperature is $T_{\mathrm{D}}$.

When $T_{\mathrm{A}}-T_{\mathrm{D}}>\Delta t$, the final state of water vapor in the air falls between $\mathrm{A}$ and $\mathrm{D}$, and the phase state of water vapor is still gaseous. At this time, the ASHP is in a neither frosting nor condensation condition.
When $T_{\mathrm{A}}-T_{\mathrm{D}} \leq \Delta t$, the final state of water vapor in the air falls in the solid-phase zone. Since it does not pass through the liquidphase zone, there is no condensation in this process, and the water vapor changes directly from gas to solid, which is sublimation. At this time, the ASHP behaves as a direct sublimation frosting condition.

In summary, according to the air temperature, the partial pressure of water vapor (or relative humidity), and the fin surface temperature, the operating conditions of the ASHP for heating in winter can be divided into four states: neither frosting nor condensation, condensation, condensation frosting, and sublimation frosting. By obtaining the meteorological parameters of a typical city in different climatic conditions, the frosting type when the city uses the ASHP for heating during the heating season can be classified.

\section{Division of Frosting Type in Typical Cities}

In this work, the meteorological data of eight cities in Nanjing, Shanghai, Wuhan, Changsha, Chongqing, Xi'an, Beijing, and Harbin were counted (meteorological data were exported by DEST-h software), and the meteorological parameters of each
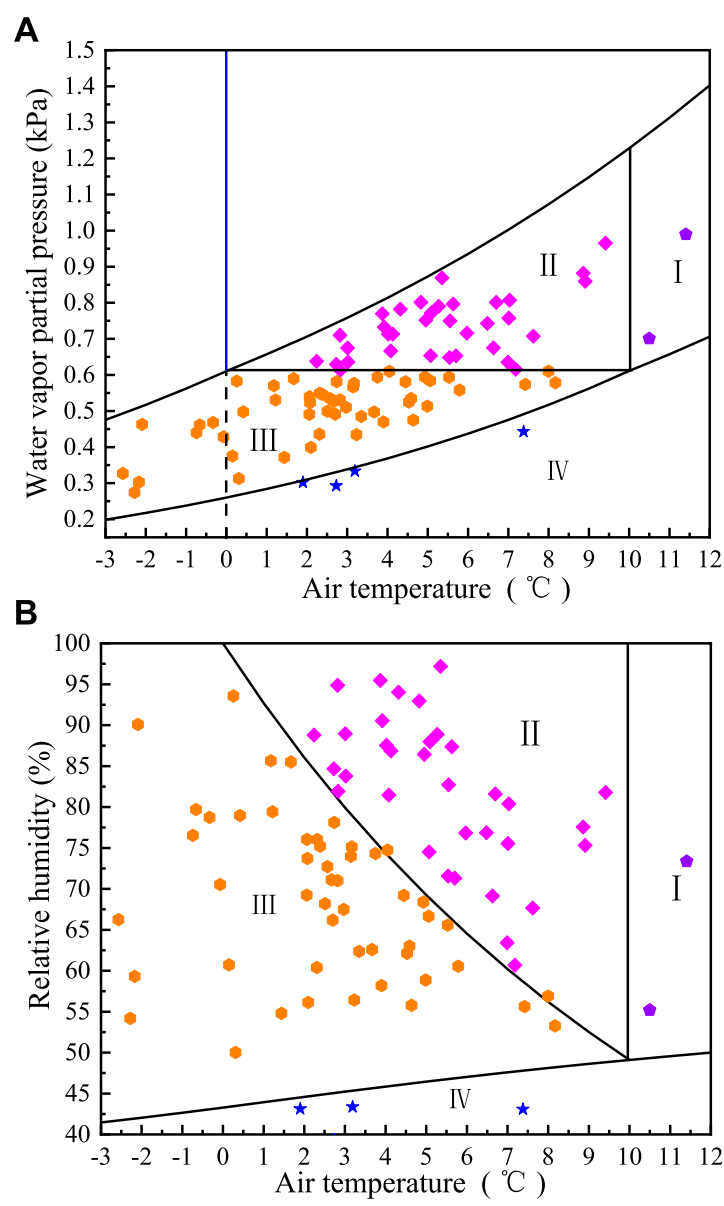

FIGURE 3 | Classification of the frosting types in Nanjing in the threephase diagram and temperature-humidity diagram: (A) three-phase diagram of water; (B) temperature-humidity diagram. 


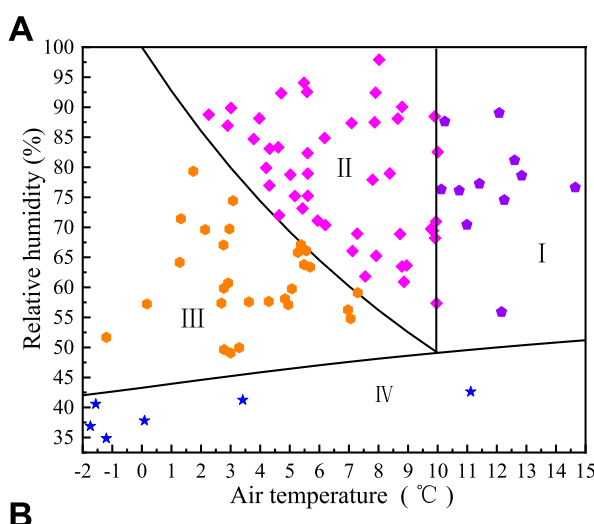

B
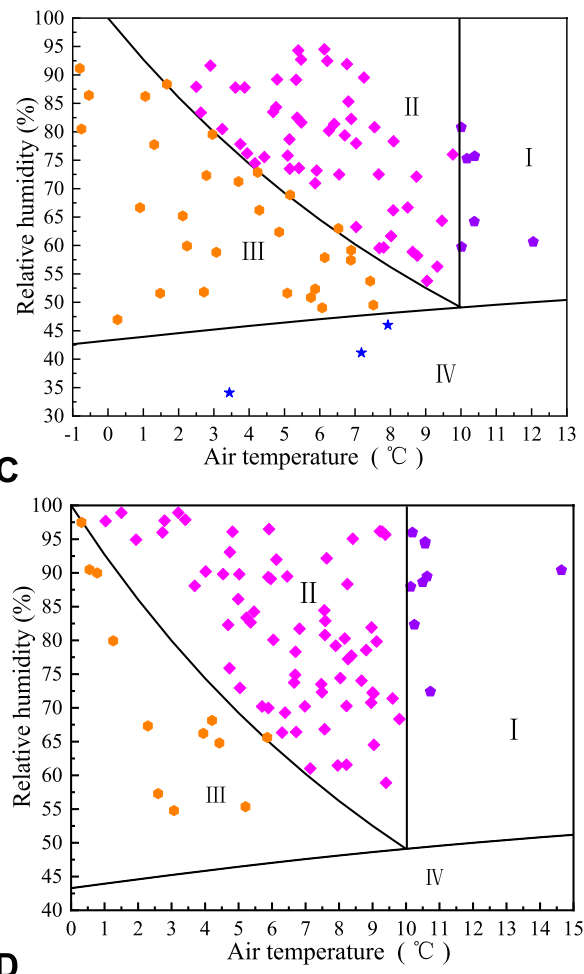

D

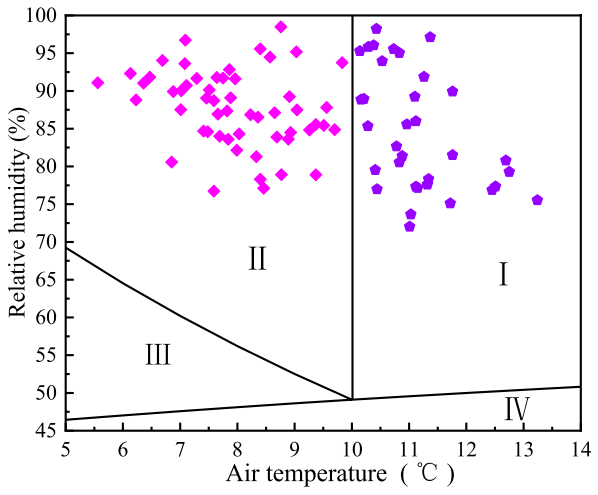

FIGURE 4 | Classification of the frosting types in Shanghai, Wuhan, Changsha, Chongqing, Xi'an, and Beijing in the temperature-humidity diagram and Harbin in the three-phase diagram: (A) Shanghai; (B) Wuhan; (C) Changsha; (D) Chongqing; (E) Xi'an; (F) Beijing; and (G) Harbin.

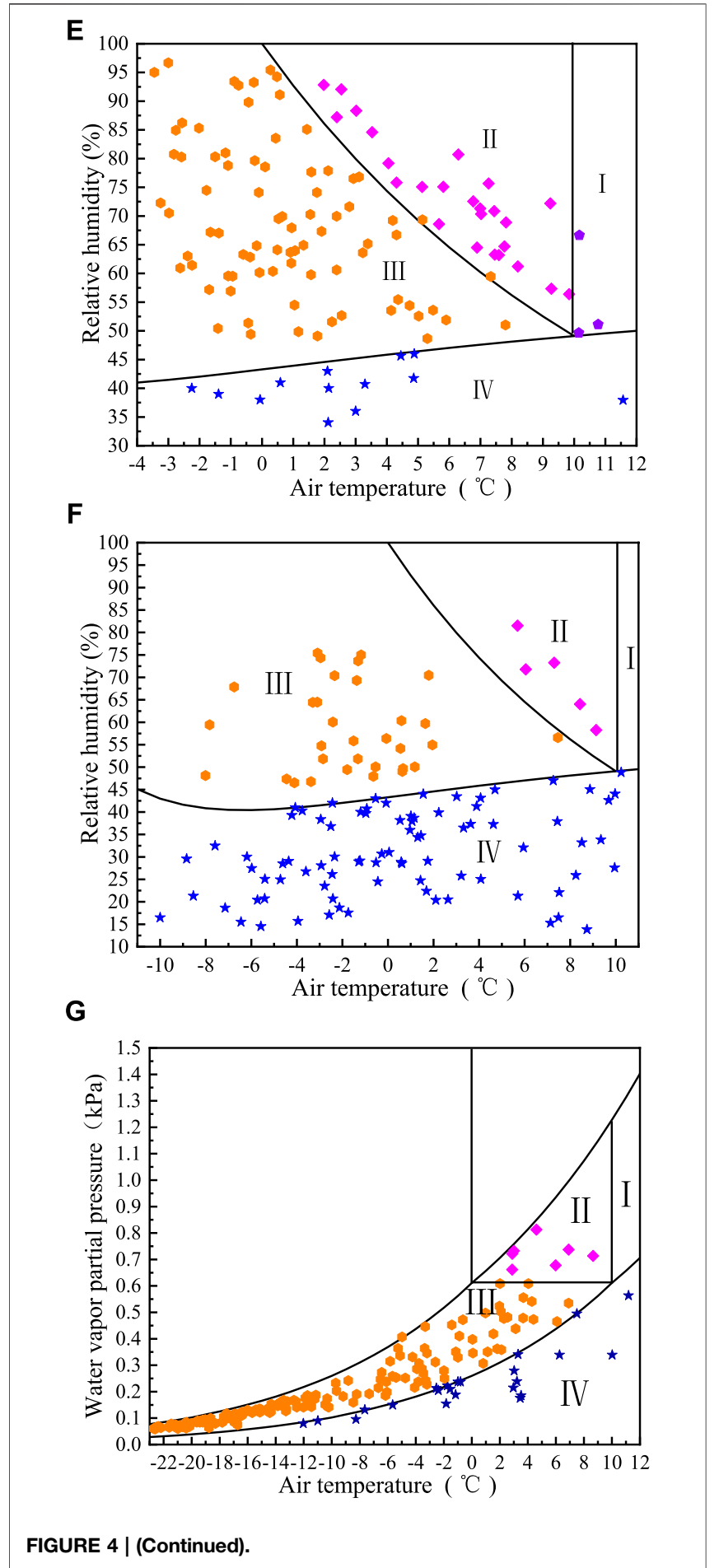

city throughout the year were obtained. The heating date was determined in accordance with the "Energy Efficiency Standards for Residential Buildings in Hot Summer and Cold Winter Areas" (JGJ 134-2010) and "Energy Efficiency Standards for Residential Buildings in Cold Areas" (JGJ 26-2010). The three-phase diagram 
TABLE 1 The proportion of frosting type in typical cities at $\Delta t=10^{\circ} \mathrm{C}$.

\begin{tabular}{|c|c|c|c|c|}
\hline City name & Condensation & $\begin{array}{l}\text { Neither frosting nor } \\
\text { condensation }\end{array}$ & Sublimation frosting & Condensation frosting (\%) \\
\hline Nanjing & $2 \%$ & $4 \%$ & $56 \%$ & 38 \\
\hline Shanghai & $12 \%$ & $7 \%$ & $31 \%$ & 50 \\
\hline Wuhan & $7 \%$ & $3 \%$ & $33 \%$ & 57 \\
\hline Changsha & $10 \%$ & 0 & 14 & 76 \\
\hline Chongqing & $38 \%$ & 0 & 0 & 62 \\
\hline Beijing & 0 & $69 \%$ & $27 \%$ & 4 \\
\hline Xi'an & $2 \%$ & $11 \%$ & $66 \%$ & 21 \\
\hline Harbin & $0 \%$ & $13 \%$ & $84 \%$ & 3 \\
\hline
\end{tabular}

of each city was achieved based on the Hyland-Wexler formula (ASHRAE, 2005). The temperature and humidity diagram was obtained by mutual calculation of the parameters of the threephase diagram of water, as shown in Figure 2. Taking Nanjing as an example, according to the JGJ 134-2010, the heating date was from December 1st to February 28th of the following year, the daily average maximum temperature during the heating season in Nanjing was $11.41^{\circ} \mathrm{C}$, and the minimum temperature was $-2.57^{\circ} \mathrm{C}$. Therefore, the temperature range of the three-phase diagram of water was $-3-12^{\circ} \mathrm{C}$. According to the daily average temperature of the heating season, the corresponding partial pressure of water vapor, and the division method of the frosting area, a map of the frosting area in Nanjing was drawn. The result is shown in Figure 3A. I zone represented the condensation area, II zone represented the condensation frosting area, III zone represented the sublimation frosting area, and IV zone represented the neither frosting nor condensation area. The critical frosting line was determined by the difference between the fin surface and the ambient air temperature, and this was always set at $10^{\circ} \mathrm{C}$ in this work. The dividing line between condensation frosting and sublimation frosting was determined by the triple-point pressure of water. The dividing line between sublimation frosting and neither frosting nor condensation was determined by the temperature of the fin surface. The corresponding temperature and humidity diagram was divided into frosting types, as shown in Figure 3B. The frosting types of Shanghai, Wuhan, Changsha, Chongqing, Xi'an, and Beijing were all temperature and humidity maps; since the lowest temperature in Harbin reached $-23^{\circ} \mathrm{C}$, the relative humidity was difficult to be expressed, and it was still expressed by a three-phase diagram, as shown in Figure 4.

When $t=-100-0^{\circ} \mathrm{C}$, the saturated water vapor partial pressure $P_{\mathrm{qb}}$ of humid air is calculated according to the following equation:

$$
\operatorname{In} P_{\mathrm{qb}}=\mathrm{C}_{1} / T+\mathrm{C}_{2}+\mathrm{C}_{3} T+\mathrm{C}_{4} T^{2}+\mathrm{C}_{5} T^{3}+\mathrm{C}_{6} T^{4}+\mathrm{C}_{7} \operatorname{In} T,
$$

where $\mathrm{C}_{1}=-5674.5359, \mathrm{C}_{2}=6.3925247, \mathrm{C}_{3}=-9.6778430 \times 10^{-3}$, $\mathrm{C}_{4}=6.2215701 \times 10^{-7}, \mathrm{C}_{5}=2.0747825 \times 10^{-9}, \mathrm{C}_{6}=-9.4840240 \times$ $10^{-13}$, and $\mathrm{C}_{7}=4.1635019$.

When $t=0-100^{\circ} \mathrm{C}$, the saturated water vapor partial pressure $P_{\mathrm{qb}}$ of humid air is calculated according tothe following equation:

$$
\operatorname{In} P_{\mathrm{qb}}=\mathrm{C}_{8} / T+\mathrm{C}_{9}+\mathrm{C}_{10} T+\mathrm{C}_{11} T^{2}+\mathrm{C}_{12} T^{3}+\mathrm{C}_{13} \operatorname{In} T,
$$

where $\mathrm{C}_{8}=-5.8002206 \times 10^{3}, \mathrm{C}_{9}=1.3914993, \mathrm{C}_{10}=-4.8640239$ $\times 10^{-2}, \mathrm{C}_{11}=4.1764768 \times 10^{-5}, \mathrm{C}_{12}=-1.4452093 \times 10^{-8}$, and $\mathrm{C}_{13}$ $=6.5459673$.

Table 1 counts the proportions of frosting type (condensation, condensation frosting, sublimation frosting, and neither frosting nor condensation) in a typical city. The sum of the two types of neither frosting nor condensation and condensation in the heating seasons of Nanjing, Shanghai, Wuhan, Changsha, Xi'an, and Harbin was less than 20\%, and more than $80 \%$ of the heating seasons would have frosting. In Beijing, 69\% of the heating seasons were neither frosting nor condensation and only $31 \%$ percent of the heating seasons were frosting. Sublimation frosting was the main frosting type in Xi'an, Beijing, and Harbin. This was mainly due to the low temperature and low humidity in the local area, which was conducive to the formation of sublimation frosting. The frosting types in Chongqing were all condensation frosting, and $38 \%$ of heating seasons were in the condensation zone. This was because Chongqing is in a mild climate zone with high humidity and high water vapor partial pressure. So, when the environment temperature is low, it will be easy for condensation frosting to occur. The frosting types in Changsha, Shanghai, and Wuhan were mainly condensation frosting, and the proportions were all more than 50\%, and they even reached $76 \%$ in Changsha, while it was mainly sublimation frosting in Nanjing and the proportion reached 56\%. Although Changsha, Shanghai, Wuhan, and Nanjing were all in the hot summer and cold winter zone, the water vapor partial pressure in Nanjing was relatively lower, resulting in a significant difference in the frosting type between Nanjing and the other three cities.

Division of frosting type can provide more accurate guidance for the suitability application of antifrosting technologies. Like superhydrophobic antifrosting technology, the suitability of superhydrophobic in condensation frosting has been confirmed, but it was not clear whether sublimation frosting can also inhibit frosting. The research results showed that the proportion of sublimation frosting in Nanjing, Shanghai, and Wuhan was more than $30 \%$ and even more than $65 \%$ in Xi'an and Beijing. Therefore, studying the mechanism of superhydrophobic antifrosting under sublimation frosting can provide a basis for the wide application of superhydrophobic antifrosting technology. 


\section{Division of Frosting Degree \\ Establishment of a Frosting Model}

The establishment of the frosting model adopted the following assumptions: 1) the frosting process was a quasi-steady-state process; that is, within the time step, the frosting process was in a steady state; 2 ) the radiative heat transfer between the frost layer and the air was ignored; 3) only considered the heat conduction in the vertical direction and ignored the thermal resistance between the tube wall and the fin; 4) the refrigerant adopted a homogeneous model; and 5) from the perspective of simplified model algorithm, ignored the pressure drop on the refrigerant side.

The total heat transferred from moist air to the frost layer includes two parts, sensible heat $Q_{\text {sen }}$ and latent heat $Q_{\text {lat }}$ :

$$
Q=Q_{\text {sen }}+Q_{\text {lat }} \text {. }
$$

Sensible heat and latent heat can also be expressed by the inlet and outlet parameters on the air side of the heat exchanger:

$$
\begin{aligned}
& Q_{\text {sen }}=h_{\mathrm{a}} A_{\mathrm{T}}\left(T_{\mathrm{a}, \mathrm{i}}-T_{\mathrm{f}}\right)=m_{\mathrm{a}} c_{\mathrm{p}, \mathrm{a}}\left(T_{\mathrm{a}, \mathrm{i}}-T_{\mathrm{a}, \mathrm{o}}\right), \\
& Q_{\mathrm{lat}}=h_{\mathrm{m}} A_{\mathrm{T}}\left(d_{\mathrm{a}, \mathrm{i}}-d_{\mathrm{f}}\right) i_{\mathrm{sv}}=m_{\mathrm{a}} i_{\mathrm{sv}}\left(d_{\mathrm{a}, \mathrm{i}}-d_{\mathrm{a}, \mathrm{o}}\right) .
\end{aligned}
$$

The air-side heat transfer coefficient of the finned tube heat exchanger can be determined by the following equations:

$$
\begin{gathered}
\operatorname{Nu}_{\mathrm{f}}=\operatorname{CRe}_{\mathrm{f}}^{n} \operatorname{Pr}_{\mathrm{f}}^{0.37}\left(\frac{\operatorname{Pr}_{\mathrm{f}}}{\operatorname{Pr}_{\mathrm{w}}}\right)^{0.25}, \\
\operatorname{Re}=\frac{u_{\mathrm{max}} d_{\mathrm{eq}}}{v_{\mathrm{a}}}, \\
h_{\mathrm{a}}=\operatorname{Nu}_{\mathrm{f}} \frac{\lambda_{\mathrm{a}}}{d_{1}} .
\end{gathered}
$$

For air, $\operatorname{Pr}_{\mathrm{f}} / \operatorname{Pr}_{\mathrm{w}} \approx 1, \operatorname{Pr}_{\mathrm{f}}^{0.38} \approx 0.88, \mathrm{C}$ and $n$ values are selected according to the Reynolds number, and the specific values are detailed in the work of Yan, 2010.

The accumulation rate of frost $m_{\mathrm{f}}$ on the surface of the heat exchanger can be expressed as (Cheng and Cheng, 2001)

$$
m_{\mathrm{f}}=h_{\mathrm{m}} A_{\mathrm{T}}\left(d_{\mathrm{a}, \mathrm{i}}-d_{\mathrm{f}}\right) .
$$

The relationship between the heat transfer coefficient and mass transfer coefficient is expressed by the Lewis number (Kuehn et al., 1998):

$$
h_{\mathrm{m}}=\frac{h_{\mathrm{a}}}{\mathrm{Le}^{2 / 3} \cdot C_{\mathrm{p} \cdot \mathrm{a}}} \text {. }
$$

Due to the porosity and molecular diffusion of frost, the mass of water vapor converted into frost is divided into two parts: one part of water vapor $m_{\rho}$ is used to increase the density of the frost layer, and the other part of water vapor $m_{\delta}$ is used to increase the thickness of the frost layer (Yao et al., 2004):

$$
m_{\mathrm{f}}=m_{\rho}+m_{\delta} .
$$

The formula for changing the density of the frost layer $m_{\rho}$ is derived (Huang et al., 2019):

$$
m_{\rho}=\frac{Q}{i_{\mathrm{sv}}+\frac{\lambda_{\mathrm{f}} T_{\mathrm{f}}^{3} R^{2}}{D_{\text {eff }} P_{\mathrm{v}}\left(i-R T_{\mathrm{f}}\right)\left[\frac{1-\left(\rho_{\mathrm{f}} / \rho_{\mathrm{i}}\right)}{1+\left(\rho_{\mathrm{f}} / \rho_{\mathrm{i}}\right)^{0.5}}\right]}} .
$$

Sherwood and Pigford (1952) proposed an empirical equation for the mass diffusion of water vapor in the air:

$$
D_{\mathrm{V}}=9.26 \times 10^{-7} \frac{1}{p_{\mathrm{a}}}\left(\frac{T^{2.5}}{T+245}\right) .
$$

Effective diffusion coefficient of water vapor on frost surface $D_{\text {eff }}$ is

$$
D_{\text {eff }}=D_{\mathrm{v}} \frac{\varepsilon}{\tau} .
$$

Porosity $\varepsilon$ is presented by the following equation (Lee and Ro, 2005):

$$
\varepsilon=\frac{\rho_{\mathrm{i}}-\rho_{\mathrm{f}}}{\rho_{\mathrm{i}}-\rho_{\mathrm{a}}}
$$

Curvature $\tau$ is presented by the following equation (Mezedur et al., 2002):

$$
\tau=\frac{\varepsilon}{1-(1-\varepsilon)^{0.5}} .
$$

The thermal conductivity of frost $\lambda_{\mathrm{f}}$ mainly depends on the density of the frost layer, which can be calculated by the correlation equation of Sanders (Sanders, 1974):

$$
\lambda_{f}=0.001202 \rho_{\mathrm{f}}^{0.963} .
$$

The density of frost is related to the surface temperature of the frost layer, and its expression is

$$
\rho_{\mathrm{f}}=650 e^{0.277\left(T_{\mathrm{f}}-273.15\right)} .
$$

The surface temperature of the frost layer can be calculated from the internal energy equation and boundary conditions of the frost layer:

$$
T_{\mathrm{f}}=T_{\mathrm{w}}+\frac{2 Q-m_{\rho} i_{\mathrm{SV}}}{2 \lambda_{\mathrm{f}} A_{\mathrm{T}}} \delta_{\mathrm{f}}
$$

For each time step $\Delta t$, the density and thickness of the frost layer change as follows:

$$
\begin{aligned}
& \Delta \rho_{\mathrm{f}}=\frac{m_{\rho} \cdot \Delta \tau}{A_{\mathrm{T}} \cdot \delta_{\mathrm{f}}}, \\
& \Delta \delta_{\mathrm{f}}=\frac{m_{\delta} \cdot \Delta \tau}{A_{\mathrm{T}} \cdot \rho_{\mathrm{f}}} .
\end{aligned}
$$

According to the frost density and thickness at the current moment plus the frost density and thickness increase in the unit time step, the frost density and thickness at the next moment can be obtained:

$$
\begin{aligned}
& \rho_{\mathrm{f}}(\tau+1)=\rho_{\mathrm{f}}(\tau)+\Delta \rho_{\mathrm{f}}(\tau), \\
& \delta_{\mathrm{f}}(\tau+1)=\delta_{\mathrm{f}}(\tau)+\Delta \delta_{\mathrm{f}}(\tau) .
\end{aligned}
$$




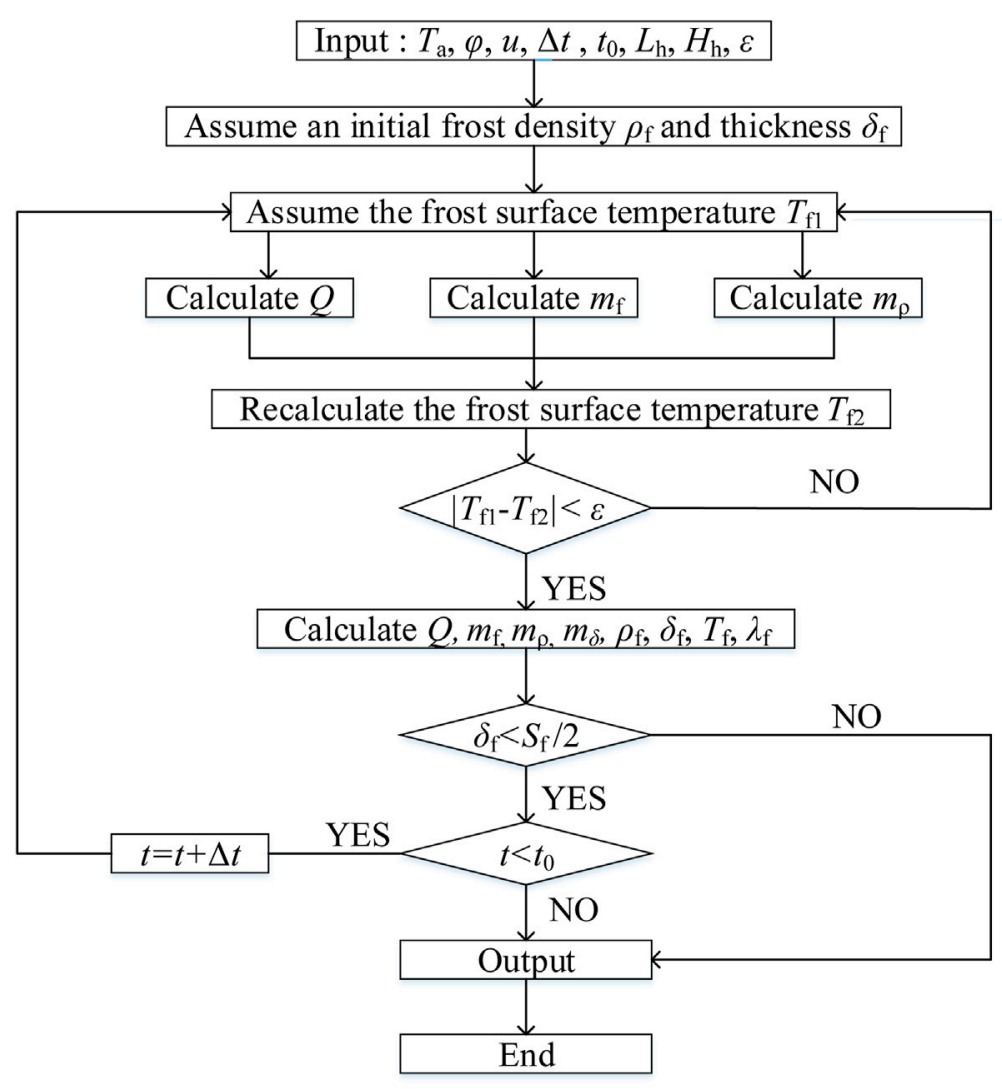

FIGURE 5 | Logic diagram of the model calculation process.

\section{Logic Diagram of the Model Calculation Process}

The calculation process of the heat exchanger model is as follows:

1) We input the size parameters of the heat exchanger and set the humid air inlet temperature, humidity, wind speed, total frosting time, time step, and iteration error. According to the wind speed range of the outdoor heat exchanger of the ASHP, the wind speed was selected as $2 \mathrm{~m} / \mathrm{s}$ in this work.

2) We assumed the initial frost density, thickness, and frost surface temperature and calculated the total heat exchange capacity and the frosting amount per unit time for the increase in frost density.

3) We recalculated the surface temperature of the frost layer according to the total heat exchange capacity and the frosting amount used to increase the density of the frost layer per unit time and used the iterative calculation method to converge the frost layer surface temperature.

4) We calculated the total heat exchange capacity, the frosting amount, the frost density and thickness, and the average thickness and density of the frost layer at this moment.

5) We judged whether the thickness of the frost layer was less than half of the minimum fin spacing and whether the frosting time was less than the set frosting time. If yes, we proceeded to the next calculation; if not, then the calculation ended, and the

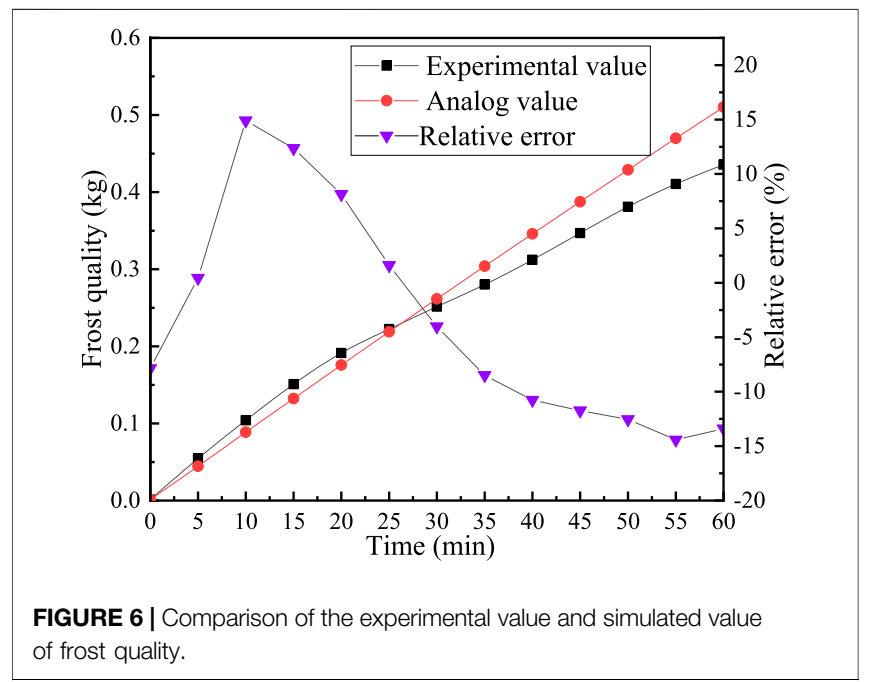

calculation results were output as required. The logic diagram of the heat exchanger frosting model is shown in Figure 5.

\section{Verification of the Frosting Model}

For a finned tube heat exchanger unit with a length of $300 \mathrm{~mm}$ and a height of $200 \mathrm{~mm}$, combined the frosting model of the heat 


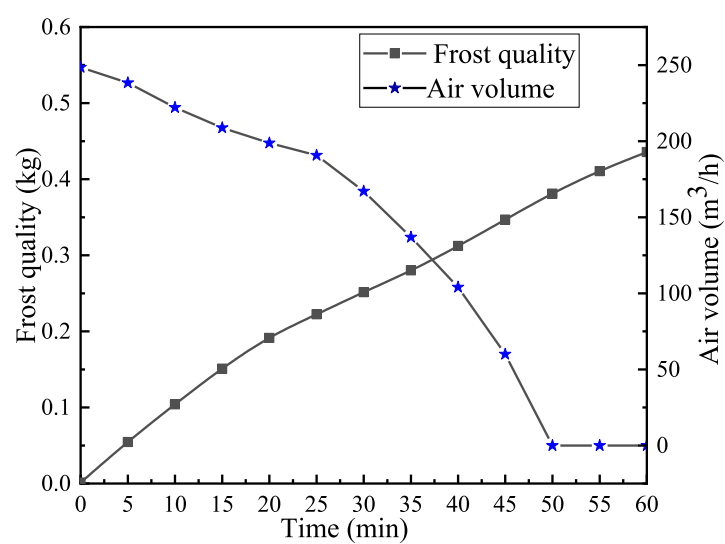

FIGURE 7 | Division principle of frosting degree according to the air volume attenuation.

exchanger, the frosting under different meteorological parameters was calculated. The structural parameters of the heat exchanger unit were as follows. The tube material was copper. The tube diameter was $10 \times 0.5 \mathrm{~mm}$. The number of wind direction tube rows was 2 , and the number of windward tube rows was 8 . The tube spacing was $25 \mathrm{~mm}$, tube row spacing $22 \mathrm{~mm}$, and the sheet spacing was $1.66 \mathrm{~mm}$. Matlab was used to program and simulate the changing law of the frosting volume of the ASHP under different working conditions. The data measured by experiment (Wang et al., 2015) and the data obtained by simulation were used to verify the reliability of the model. The comparison result is shown in Figure 6. Experimental values and simulation values are carried out at air temperature $T_{\mathrm{a}}=0^{\circ} \mathrm{C}$ and relative humidity $\varphi=90 \%$.

It is seen from Figure 6 that the relative error between the experimental value and the simulated value was within $15 \%$. This was because the ethylene glycol aqueous solution was used as the refrigerant for heat exchange in the experiment, and the phase state of the refrigerant used in the simulation changed. The frictional resistance loss of the glycol aqueous solution was greater than that of the refrigerant under low-temperature conditions, and the heat exchange effect was worse than that of the refrigerant.

\section{Method for Division of Frosting Degree}

The frosting model had been verified above, and it was found that the frosting model was reliable. The experiment measured the change of frost quality and air volume with time under air temperature $0^{\circ} \mathrm{C}$ and relative humidity $90 \%$. It was found that the air volume attenuation amplitude increased when the time was $25 \mathrm{~min}$, and the corresponding frost quality was $0.223 \mathrm{~kg}$, when the time reached $50 \mathrm{~min}$, the air volume decreased sharply, and the corresponding frost quality was $0.381 \mathrm{~kg}$. For this reason, we choose the frost quality corresponding to 25 and $50 \mathrm{~min}$ as the air source frosting mild, moderate, and severe to divide the frosting degree of different typical cities under different working conditions. We calculated the daily frosting quality during the heating season with Matlab and first compared it
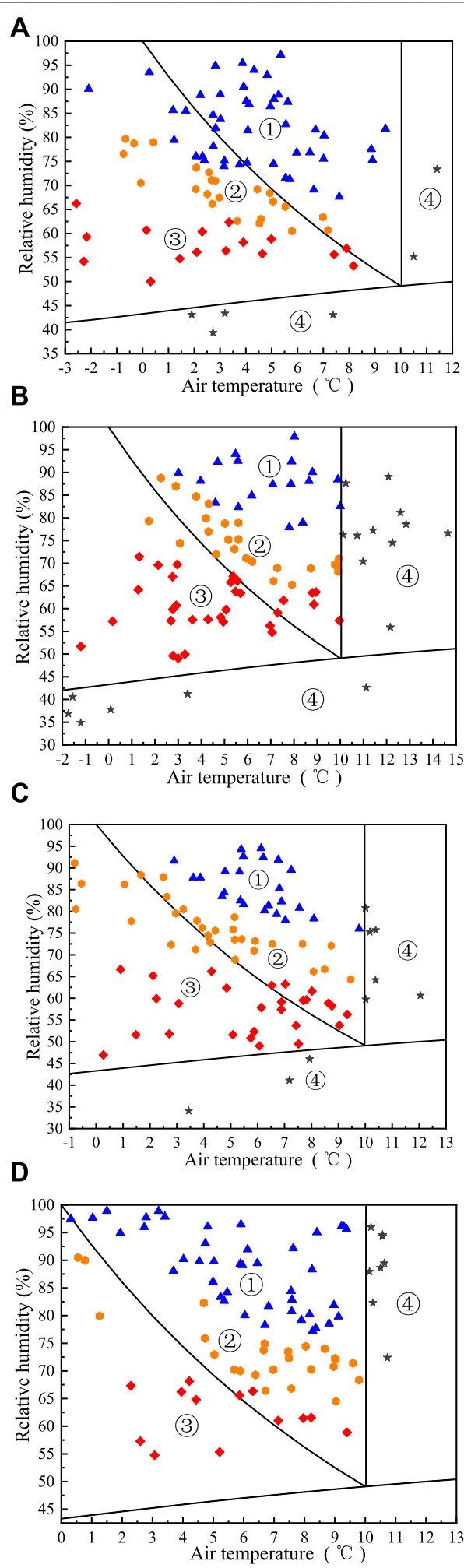

FIGURE 8 | Classification of the frosting degree in Nanjing, Shanghai, Wuhan, Changsha, Chongqing, Xi'an, and Beijing in the temperature-humidity diagram and Harbin in the three-phase diagram: (A) Nanjing; (B) Shanghai; (C) Wuhan; (D) Changsha; (E) Chongqing; (F) Xi'an; (G) Beijing; and (H) Harbin. 


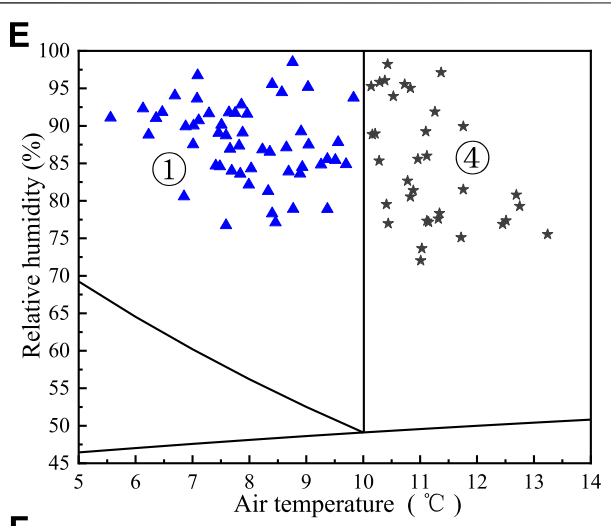

$\mathbf{F}$

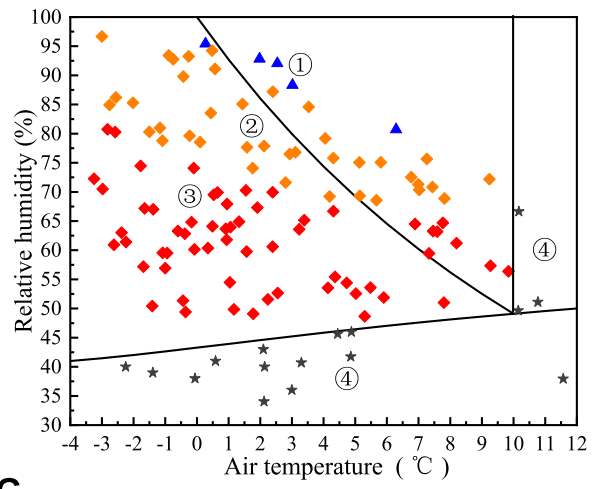

$\mathbf{G}$

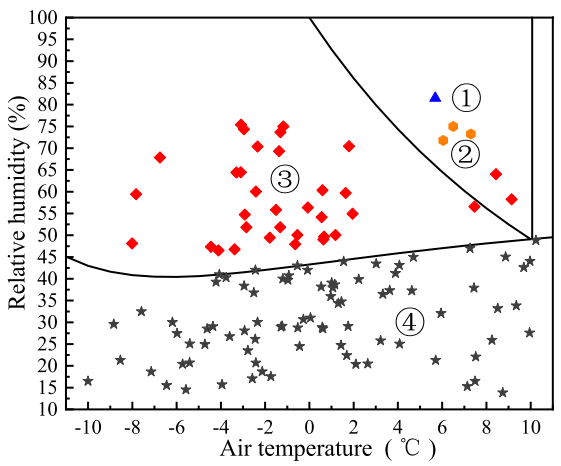

H

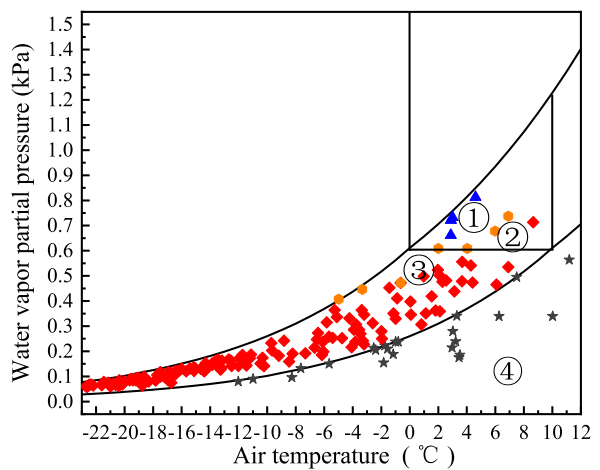

FIGURE 8 | (Continued).

with the frosting quality of $0.223 \mathrm{~kg}$ corresponding to $25 \mathrm{~min}$; if it was less than $0.223 \mathrm{~kg}$, it was mild frosting, if it was between 0.223 and $0.381 \mathrm{~kg}$, it was moderate frosting, and if it was greater than
$0.381 \mathrm{~kg}$, it was heavy frosting. The method of dividing the frosting degree is shown in Figure 7.

\section{Division Results and Analysis}

The results of dividing the frosting degree area of the ASHP in each typical cities are shown in Figure 8: (1) represented the nonfrosting area; (2) represented the mild frosting area; (3) represented the moderate frosting area; and (4) represented the heavy frosting area. Harbin was still expressed by a three-phase diagram.

Table 2 counts the proportion of frosting degree in a typical city in the nonfrosting area, mild frosting area, moderate frosting area, and heavy frosting area. It could be seen from Figure 8 that about $50 \%$ of the heating seasons in Nanjing and Changsha were distributed in the heavy frost area and 100\% in Chongqing. Furthermore, the heavy frosting area was almost always under the type of condensation frosting. It was shown that the ASHP was running in the abovementioned area, it was easy to condensation, and once it frosted, the frost layer grew very quickly, so defrosting operations were required quite frequently. The proportion of mild frosting in Shanghai is about $42 \%$, followed by moderate frosting about $33 \%$. The proportions of the three frosting degrees in Wuhan were close. The heating seasons of Beijing, Xi'an, and Harbin were dominated by mild frosting, reaching 89,57 , and $94 \%$, respectively, and it was basically under the sublimation frosting, mainly because the climate in these cities was relatively dry. Although the ASHP would frost during operation, the amount of frosting was small, and the frequency of defrosting was required to be low. The proportion of the nonfrosting area is the sum of the proportion of condensation and neither frosting nor condensation in the frosting type.

\section{CONCLUSION}

This paper divided the frosting type into four types. Based on the statistics of the meteorological parameters of each typical city, the division of frosting type was obtained. On the basis of the classification of frosting type, the two types of condensation frosting and sublimation frosting were divided into mild frosting, moderate frosting, and heavy frosting. The frosting conditions in different heating seasons in different cities were evaluated, and the following conclusions were drawn:

1) More than $80 \%$ of the heating seasons in Nanjing, Shanghai, Wuhan, Changsha, Xi'an, and Harbin would have frosting. About $50 \%$ of the heating seasons in Nanjing and Changsha were distributed in the heavy frost area and $100 \%$ in Chongqing. For Nanjing and other hot summer and winter cold areas, the outdoor temperature and defrosting should be corrected to reduce the effect of frosting on the surface of the evaporator on the performance of the unit. For Chongqing and other high humidity areas (Yang et al., 2020), the outdoor temperature for heating in winter should be above $8^{\circ} \mathrm{C}$ and defrosting in stages below $6^{\circ} \mathrm{C}$ should be considered to improve the performance of the ASHP.

2) The types of frosting in Changsha, Shanghai, and Wuhan were mainly condensation frosting, and the proportions were all more than 50\%, and it even reached 76\% in Changsha, while in 
TABLE 2 | The proportion of frosting degree in typical cities.

\begin{tabular}{|c|c|c|c|c|}
\hline City name & Severe frosting (\%) & Moderate frosting (\%) & Mild frosting (\%) & Nonfrosting (\%) \\
\hline Nanjing & 54 & 27 & 19 & 6 \\
\hline Shanghai & 25 & 33 & 42 & 19 \\
\hline Wuhan & 30 & 37 & 33 & 10 \\
\hline Changsha & 53 & 32 & 15 & 10 \\
\hline Chongqing & 100 & 0 & 0 & 38 \\
\hline Beijing & 3 & 8 & 89 & 69 \\
\hline Xi'an & 5 & 38 & 57 & 13 \\
\hline Harbin & 2 & 4 & 94 & 13 \\
\hline
\end{tabular}

Nanjing, it was mainly sublimation frosting and the proportion reached $56 \%$. The water vapor partial pressure in Nanjing was relatively lower, resulting in a significant difference in the frosting type between Nanjing and the other three cities.

3) The types of frosting in the heating seasons in Xi'an, Beijing, and Harbin were mainly sublimation frosting, and the frosting degree is mainly light frosting, reaching 57, 89, and 94\%, respectively. This was mainly due to the low temperature and low humidity in the local area, which was conducive to the formation of sublimation frosting. The amount of frosting was small, and the frequency of defrosting was required to be low.

\section{DATA AVAILABILITY STATEMENT}

The raw data supporting the conclusions of this article will be made available by the authors, without undue reservation.

\section{REFERENCES}

Amer, M., and Wang, C.-C. (2017). Review of Defrosting Methods. Renew. Sust. Energ. Rev. 73, 53-74. doi:10.1016/j.rser.2017.01.120

ASHRAE (2005). Fundamentals. American Society of Heating, Refrigerating and Air-Conditioning Engineers, Inc., 1971 Tullie Circle, N.E., Atlanta, GA 30329.

Cheng, C.-H., and Cheng, Y.-C. (2001). Predictions of Frost Growth on a Cold Plate in Atmospheric Air. Int. Commun. Heat Mass Transfer. 28, 953-962. doi:10.1016/s0735-1933(01)00299-8

Dong, J., Deng, S., Jiang, Y., Xia, L., and Yao, Y. (2012). An Experimental Study on Defrosting Heat Supplies and Energy Consumptions During a Reverse Cycle Defrost Operation for an Air Source Heat Pump. Appl. Therm. Eng. 37, 380-387. doi:10.1016/j.applthermaleng.2011.11.052

Guo, X. M., Wang, C. S., and Wang, W. H. (2006). Numerical Simulation and Experimental Verification on Dynamic Performance of Air Source Heat Pump Under Frosting Conditions. J. Xi'an Jiaotong Univ. 40 (5), 544-548. [In Chinese]. doi:10.1016/S1872-1508(06)60066-1

Huang, W., Zhang, T., Ji, J., and Xu, N. (2019). Numerical Study and Experimental Validation of a Direct-Expansion Solar-Assisted Heat Pump for Space Heating under Frosting Conditions. Energy. Build. 185, 224-238. doi:10.1016/ j.enbuild.2018.12.033

Kim, H., Kim, D., Jang, H., Kim, D. R., and Lee, K.-S. (2016). Microscopic Observation of Frost Behaviors at the Early Stage of Frost Formation on Hydrophobic Surfaces. Int. J. Heat Mass Transfer. 97, 861-867. doi:10.1016/ j.ijheatmasstransfer.2016.02.020

Kuehn, T. H., Ramsey, J. W., and Threlkeld, J. L. (1998). Thermal Environmental Engineering. Upper Saddle River, NJ: Prentice-Hall.

Lee, J., and Lee, K.-S. (2018). The Behavior of Frost Layer Growth Under Conditions Favorable for Desublimation. Int. J. Heat Mass Transfer. 120, 259-266. doi:10.1016/j.ijheatmasstransfer.2017.12.039

\section{AUTHOR CONTRIBUTIONS}

RT: conceptualization, methodology, software, formal analysis, and writing. FW: validation, writing-review and editing, supervision, and funding acquisition. ZW: visualization, data curation, and writing. WY: writing-review and editing.

\section{FUNDING}

This work was supported by the National Natural Science Foundations of China (No. 52006186), the China Postdoctoral Science Foundation funded project (No. 2020M681453), the Natural Science Foundation of the Jiangsu Higher Education Institutions of China (No. 19KJB470037), Jiangsu Planned Projects for Postdoctoral Research Funds (No. 2020Z303), and the "Green Yang Jin Feng" Project of Yangzhou City.

Lee, Y. B., and Ro, S. T. (2005). Analysis of the Frost Growth on a Flat Plate by Simple Models of Saturation and Supersaturation. Exp. Therm. Fluid Sci. 29, 685-696. doi:10.1016/j.expthermflusci.2004.11.001

Li, L., Liu, Z., Li, Y., and Dong, Y. (2017). Frost Deposition on a Horizontal Cryogenic Surface in Free Convection. Int. J. Heat Mass Transfer. 113, 166-175. doi:10.1016/j.ijheatmasstransfer.2017.05.058

Mezedur, M. M., Kaviany, M., and Moore, W. (2002). Effect of Pore Structure, Randomness and Size on Effective Mass Diffusivity. Aiche J. 48, 15-24. doi:10.1002/aic.690480104

Sanders, C. T. (1974). The influence of frost formation and defrosting on the performance of air coolers. Technische Hogeschool, Delft, Nether Lands. PhD thesis.

Sherwood, T. K., and Pigford, R. L. (1952). Absorption and Extraction. New York, NY: McGraw-Hill.

Song, M., Deng, S., Dang, C., Mao, N., and Wang, Z. (2018). Review on Improvement for Air Source Heat Pump Units During Frosting and Defrosting. Appl. Energ. 211, 1150-1170. doi:10.1016/j.apenergy.2017.12.022

Song, M., Mao, N., Deng, S., Chen, Y., Wang, C., and Yang, Q. (2016). Experimental Investigations on Destroying Surface Tension of Melted Frost for Defrosting Performance Improvement of a Multi-Circuit Outdoor Coil. Appl. Therm. Eng. 103, 1278-1288. doi:10.1016/j.applthermaleng.2016.03.173

Wang, F., Liang, C., Yang, M., Fan, C., and Zhang, X. (2015). Effects of Surface Characteristic on Frosting and Defrosting Behaviors of Fin-Tube Heat Exchangers. Appl. Therm. Eng. 75, 1126-1132. doi:10.1016/j.applthermaleng.2014.10.090

Wang, J. F. (1997). Study of Frosting Characteristics of Air Source Heat Pumps During winter Heating. Refrig 58, 8-11. [In Chinese].

Wang, W., Zhang, F. R., Guo, Q. C., Xiao, J., and Zhao, Y. H. (2009). Investigation of Frost Status for Air Source Heat Pump in Different Regions of China. J. Hunan Univ. Natl. Sci. 36, 9-13. [In Chinese].

Wang, Z., Wang, F., Ma, Z., and Song, M. (2017). Numerical Study on the Operating Performances of a Novel Frost-free Air-Source Heat Pump Unit 
Using Three Different Types of Refrigerant. Appl. Therm. Eng. 112, 248-258. doi:10.1016/j.applthermaleng.2016.10.040

Wu, X. M., Ma, Q., and Chu, F. Q. (2017). Numerical Simulation of Frosting on Fin-And-Tube Heat Exchanger Surfaces. J. Therm. Sci Eng Appl. 9, 031007. doi:10.1115/1.4035925

Xu, X., Fang, Z., and Wang, Z. (2020). Climatic Division Based on Frosting Characteristics of Air Source Heat Pumps. Energy. Build. 224, 110219. doi:10.1016/j.enbuild.2020.110219

Yan, Q. S. (2010). Refrigeration Technology for Air Conditioning. Beijing. China Construction Industry Press. [In Chinese].

Yang, Y. X., Mao, R. Y., Zhao, Q., Hu, C., and Tian, M. J. (2020). Research on Frosting Law and Frost Suppression Strategy of Air Source Heat Pump in Guiyang Area. Energ Conserv Tech. 38, 90-96. [In Chinese]. doi:10.1088/1755-1315/495/1/012006

Yao, Y., Jiang, Y. Q., Deng, S. M., and Ma, Z. L. (2004). A Study on the Performance of the Airside Heat Exchanger under Frosting in an Air Source Heat Pump Water Heater/chiller Unit. Int. J. Heat Mass. Transfer. 47, 17-18. doi:10.1016/ j.ijheatmasstransfer.2004.03.013

Yu, L. X., Fu, X. Z., and Xiao, Y. M. (2011). Climate suitability of air-source heat pumps in Yangtze valley. HVઐAC. 41, 96-99. [In Chinese]. doi:10.3969/ j.issn.1002-8501.2011.06.024

Zhang, L., Dong, J., Jiang, Y., Deng, S., and Huang, S. (2018b). An Experimental Study on Frosting and Defrosting Performances of a Novel Air Source Heat Pump Unit with a Radiant-Convective Heating Terminal. Energy. Build. 163, 10-21. doi:10.1016/j.enbuild.2017.12.035 doi:10.1016/j.enbuild.2017.12.035
Zhang, L., Jiang, Y., Dong, J., and Yao, Y. (2018a). Advances in Vapor Compression Air Source Heat Pump System in Cold Regions: A Review. Renew. Sust Energ. Rev. 81, 353-365. doi:10.1016/j.rser.2017.08.009 Zhang, Q., Zhang, L., Nie, J., and Li, Y. (2017). Techno-economic Analysis of Air Source Heat Pump Applied for Space Heating in Northern China. Appl. Energ. 207, 533-542. doi:10.1016/j.apenergy.2017.06.083

Conflict of Interest: The authors declare that the research was conducted in the absence of any commercial or financial relationships that could be construed as a potential conflict of interest.

Publisher's Note: All claims expressed in this article are solely those of the authors and do not necessarily represent those of their affiliated organizations, or those of the publisher, the editors and the reviewers. Any product that may be evaluated in this article, or claim that may be made by its manufacturer, is not guaranteed or endorsed by the publisher.

Copyright (c) 2021 Tang, Wang, Wang and Yang. This is an open-access article distributed under the terms of the Creative Commons Attribution License (CC BY). The use, distribution or reproduction in other forums is permitted, provided the original author(s) and the copyright owner(s) are credited and that the original publication in this journal is cited, in accordance with accepted academic practice. No use, distribution or reproduction is permitted which does not comply with these terms. 


\section{NOMENCLATURE}

$\boldsymbol{P}$ Pressure $(\mathrm{Pa})$

Q Total heat exchange (W)

$\boldsymbol{A}_{\mathbf{T}}$ Air-side heat transfer area $\left(\mathrm{m}^{2}\right)$

$\boldsymbol{T}$ Temperature $\left({ }^{\circ} \mathrm{C}\right)$

$\boldsymbol{d}$ Moisture content $(\mathrm{kg} /(\mathrm{kg} \cdot \mathrm{a}))$

$\boldsymbol{m}_{\mathbf{a}}$ Air mass flow $(\mathrm{kg} / \mathrm{s})$

$\boldsymbol{i}_{\text {sv }}$ Latent heat of sublimation of water vapor $(\mathrm{J} / \mathrm{kg})$

$\boldsymbol{C}_{\mathbf{p} \cdot \mathbf{a}}$ Air heat capacity at constant pressure $(\mathrm{J} /(\mathrm{kg} \cdot \mathrm{K}))$

$\boldsymbol{h}_{\mathbf{a}}$ Air-side heat transfer coefficient $\left(\mathrm{W} /\left(\mathrm{m}^{2} \cdot \mathrm{K}\right)\right)$

$\boldsymbol{h}_{\mathbf{m}}$ Mass transfer coefficient $\left(\mathrm{kg} /\left(\mathrm{m}^{2} \cdot \mathrm{K}\right)\right)$

$\boldsymbol{N u}$ Nusselt number

$\boldsymbol{R} \boldsymbol{e}$ Reynolds number

Pr Prandtl number

$\boldsymbol{d}_{\mathbf{1}}$ Copper tube outer diameter $(\mathrm{mm})$

$\boldsymbol{L}_{\mathbf{h}}$ The length of the heat exchanger (mm)

$\boldsymbol{H}_{\mathbf{h}}$ The height of the heat exchanger (mm)

$\boldsymbol{S}_{\mathbf{f}}$ The minimum fin spacing $(\mathrm{mm})$

$\boldsymbol{v}_{\text {a }}$ Air kinematic viscosity $\left(\mathrm{m}^{2} / \mathrm{s}\right)$

$\boldsymbol{d}_{\mathbf{e q}}$ Equivalent diameter (mm) $\boldsymbol{u}_{\max }$ Air velocity at the narrowest point $(\mathrm{m} / \mathrm{s})$

Le Lewis number

$\boldsymbol{R}$ Water vapor gas constant $(\mathrm{J} /(\mathrm{kg} \cdot \mathrm{K}))$

$D_{\text {eff }}$ Effective diffusion coefficient of water vapor on the frost surface $\left(\mathrm{m}^{2} / \mathrm{s}\right)$

$\boldsymbol{D}_{\mathbf{v}}$ Frost surface water vapor diffusion coefficient $\left(\mathrm{m}^{2} / \mathrm{s}\right)$

$\rho$ Density $\left(\mathrm{kg} / \mathrm{m}^{3}\right)$

$\boldsymbol{\varepsilon}$ Porosity

$\tau$ Curvature

\section{Greek letters}

$\boldsymbol{\delta}$ Thickness (m)

$\lambda$ Thermal conductivity $(\mathrm{W} /(\mathrm{m} \cdot \mathrm{K}))$

\section{SUBSCRIPT}
a Air
f Frost layer
a,i Air-side inlet
a,o Air-side outlet
i Ice
w Wall
v Vapor 